\title{
VALIDATION OF A SMARTPHONE APPLICATION FOR THE MEASUREMENT OF HEART RATE DURING EXERCISE
}

original paper

(1) University School of Physical Education in Wroclaw

DOI: https://doi.org/10.5114/hm.2020.89911

\section{GUSTAVO CÉSAR VASCONCELOS, IGOR RODRIGUES DAMORIM, TONY MEIRELES SANTOS, THIAGO LIMA, RODOLFO SANTOS, ADRIANO LIMA, VINICIUS DAMASCENO}

Federal University of Pernambuco, Recife, Brazil

\begin{abstract}
Purpose. To verify the validity of Instant Heart Rate ${ }^{\circledR}$ application in smartphones for the measurement of exercise heart rate. Methods. The individuals were initially instructed about all the procedures to be performed and signed the consent form. Anthropometric measures and rest heart rate were evaluated before the experimental session of the study. The subjects participated in a self-selected exercise on a cycle ergometer for 10 minutes.

Results. The results for validity demonstrated in an iPhone/iOS ${ }^{\circledR}$ smartphone revealed the intra-class correlation coefficient of $r=0.87$ with a tendency to overestimate the heart rate by $5 \mathrm{bpm}$. For the Lenovo/Android ${ }^{\circledR}$ model, the intra-class correlation coefficient was $r=0.98$, underestimating the values by $-0.7 \mathrm{bpm}$. Thus, both systems presented high correlation values, and the error observed did not seem to compromise the several measures that use heart rate as a parameter.

Conclusions. It is possible to conclude that heart rate monitoring by the Instant Heart Rate ${ }^{\circledR}$ application on iPhone/iOS ${ }^{\circledast}$ and Lenovo/Android ${ }^{\circledR}$ operating system smartphones can be performed safely during exercise, with the Lenovo/Android ${ }^{\circledR}$ base being even more reliable than the iPhone/iOS ${ }^{\circledR}$ system.
\end{abstract}

Key words: haemodynamics, smartphone applications, validity of tests, technology

\section{Introduction}

Heart rate (HR) is the most commonly used physiological variable in physical training. It assists in the control of training intensities $[1,2]$, the prediction of maximal aerobic power [3], the estimation of training intensity [4], and the measurements obtained in relation to exercise and cardiovascular health $[5,6]$. HR measurement methods during exercise include the palpatory method, the electrocardiogram (ECG), and HR monitors (HRMs), which have been widely used by researchers and coaches owing to the simplicity of their application [7].

HRMs, although practical, are slowly being replaced by devices that offer all the functionalities expected in the modern life, allow social interactions and goal setting, and provide real-time feedback of an indi- vidual's performance [8]. This replacement is a result of the great technological advances of smartphones. Currently, smartphones, in addition to their function as cell phones, are pocket-sized mini-computers with an extremely large number of applications and countless sensors such as accelerometers, global positioning systems, and travel speed detectors. Smartphones have facilitated accessibility for the measurement of several physiological and biomechanical variables such as movement speed [9], jump height [10, 11], HR [12], blood pressure, and blood glucose [13]. Because of advancements in technology, the variety of applications available on digital platforms have increased the use of smartphones, allowing the measurement of physiological variables such as HR monitoring at rest and during physical exercise [5, 14]. HR data are collected by video cameras that are accompanied by tools

Correspondence address: Vinicius de Oliveira Damasceno, Universidade Federal de Pernambuco, Campus Recife, Departamento de Educação Física, Avenida Jornalista Aníbal Fernandes, s/n, 50670-901, Recife, PE, Brazil, e-mail: vinicius.damasceno@ufpe.br

Received: May 24, 2019

Accepted for publication: October 3, 2019

Citation: Vasconcelos GC, Damorim IR, Santos TM, Lima T, Santos R, Lima A, Damasceno V. Validation of a smartphone application for the measurement of heart rate during exercise. Hum Mov. 2020;21(2):25-31; doi: https://doi.org/10.5114/ hm.2020.89911. 
that emit light beams to capture the bio-optical image reflection of the illuminated target tissue $[15,16]$.

For these measurements to be applied in the assessment of health and physical performance components, data must reflect the actual values of what they are intended to measure. Therefore, the set, smartphone, and application must undergo psychometric analysis to determine the validity of the reported measurement. Previous studies have shown a strong correlation between the Instant Heart Rate ${ }^{\circledast}$ application (v. 5.36.2819, Azumio Inc., Redwood City, USA) and ECG in rest $(r=0.83)$ [17] and inconsistent correlations during exercise, with $r$ values varying between -0.09 and 0.81 for each exercise stage [18]. However, these studies were based on the iOS $^{\oplus}$ operating system, which can be modified into other operating systems. On the other hand, another study used the intra-class correlation coefficient (ICC) to determine the validity of measurements before and after climbing stairs. The results showed a high degree of concurrent validity with the Polar ${ }^{\circledast}$ device (ICC > 0.90) for the measures pre- and post-exercise, but there was no assessment during exercise [19].

Thus, the purpose of the present study was to establish the validity of the Instant Heart Rate ${ }^{\circledast}$ application (v. 5.36.2819, Azumio Inc., Redwood City, USA) in the smartphone operating system of Android ${ }^{\circledast}$ and iPhone $/ \mathrm{iOS}^{\otimes}$ for the measurement of HR during exercise in university students.

\section{Material and methods}

\section{Participants}

The participants were selected for convenience; the group consisted of 48 individuals of both sexes (males: $n=24$, females: $n=24$; age: $21.7 \pm 1.0$ years; body height: $1.68 \pm 0.10 \mathrm{~m}$; body mass: $69.5 \pm 11.4$ $\mathrm{kg}$ ). Data were collected at the Federal University of Pernambuco from January to October 2016. The inclusion criteria were as follows: subjects of both sexes, 18-35 years of age, and physical education students. We did not include individuals who used drugs and/ or had diseases that caused changes in cardiovascular responses. The participants were instructed not to drink beverages containing caffeine or other stimulants or relaxants of the sympathetic nervous system and not to perform vigorous exercise 24 hours before data collection. All individuals were informed about the procedures to be performed, as well as about the benefits and risks of the investigation before signing the informed consent form. The statistical power of the analysis was calculated by using the $G^{*}$ Power software (v. 3.1.7). An effect size of 0.4 with an $\alpha$ error probability of 0.05 , a $\beta$ error probability of 0.95 , and actual power of 0.95 were determined.

\section{Procedures}

To establish the Instant Heart Rate ${ }^{\circledR}$ application validity, we conducted a cross-sectional and methodological study that was oriented towards determining the psychometric limits of the quality of the instrument. Only one visit was necessary to collect the data. Anthropometric measures and resting HR were assessed, following which the subjects were submitted to an exercise session on a cycle ergometer with their HR measured by using an HRM and the Instant Heart Rate $^{\circledast}$ application in the iPhone/iOS ${ }^{\circledast}$ and Lenovo/Android $^{\otimes}$ smartphones simultaneously.

\section{Anthropometrics}

To characterize the sample, body mass (balance by Filizola $^{\circledR}$, Brazil) and stature (stadiometer) measurements were performed with a precision of $0.1 \mathrm{~kg}$ and $1 \mathrm{~mm}$, respectively. Body mass index was calculated from the ratio: body mass $(\mathrm{kg}) /$ stature $(\mathrm{m})^{2}$.

\section{Heart rate}

The following 3 instruments were used for HR measurements: (1) HRM Polar ${ }^{\circledR}$ (RS800CX, Electro Oy, Kempele, Finland); there is ample evidence that the pulse rate data obtained via Polar ${ }^{\circledast}$ devices are strongly correlated (0.85-0.99) with ECG and a typical error of measurement is $0.6 \mathrm{bpm}$ compared with ECG [16, 17]; (2) iPhone 5.0 (iOS ${ }^{\circledR} 7.1$ ); and (3) Lenovo Vibe K5 (Android ${ }^{\circledR} 5.0$ Lollipop $^{\circledR}$ ). The measurement of HR by the HRM followed the manufacturer's recommendations as follows: the elastic band with the electrodes was humidified and adjusted to the chest, just below the pectoral muscles. The HR measurement with the smartphones followed the standardization of the Instant Heart Rate ${ }^{\circledR}$ application (Instant Heart Hate ${ }^{\circledR}$, v. 5.36.2819, Azumio Inc., Redwood City, USA).

Data collection was initiated with the placement of the HRM elastic strip. The participant was then seated for 5 min to stabilize their HR. After stabilization, the subject sat on an ergometric bicycle. The familiarization with the HR measurement was performed through the brackets coupled to the cycle ergometer for the best hand support, which facilitated the HR reading (Figure 1). During this activity, HR collections were performed simultaneously via the 3 instruments. 


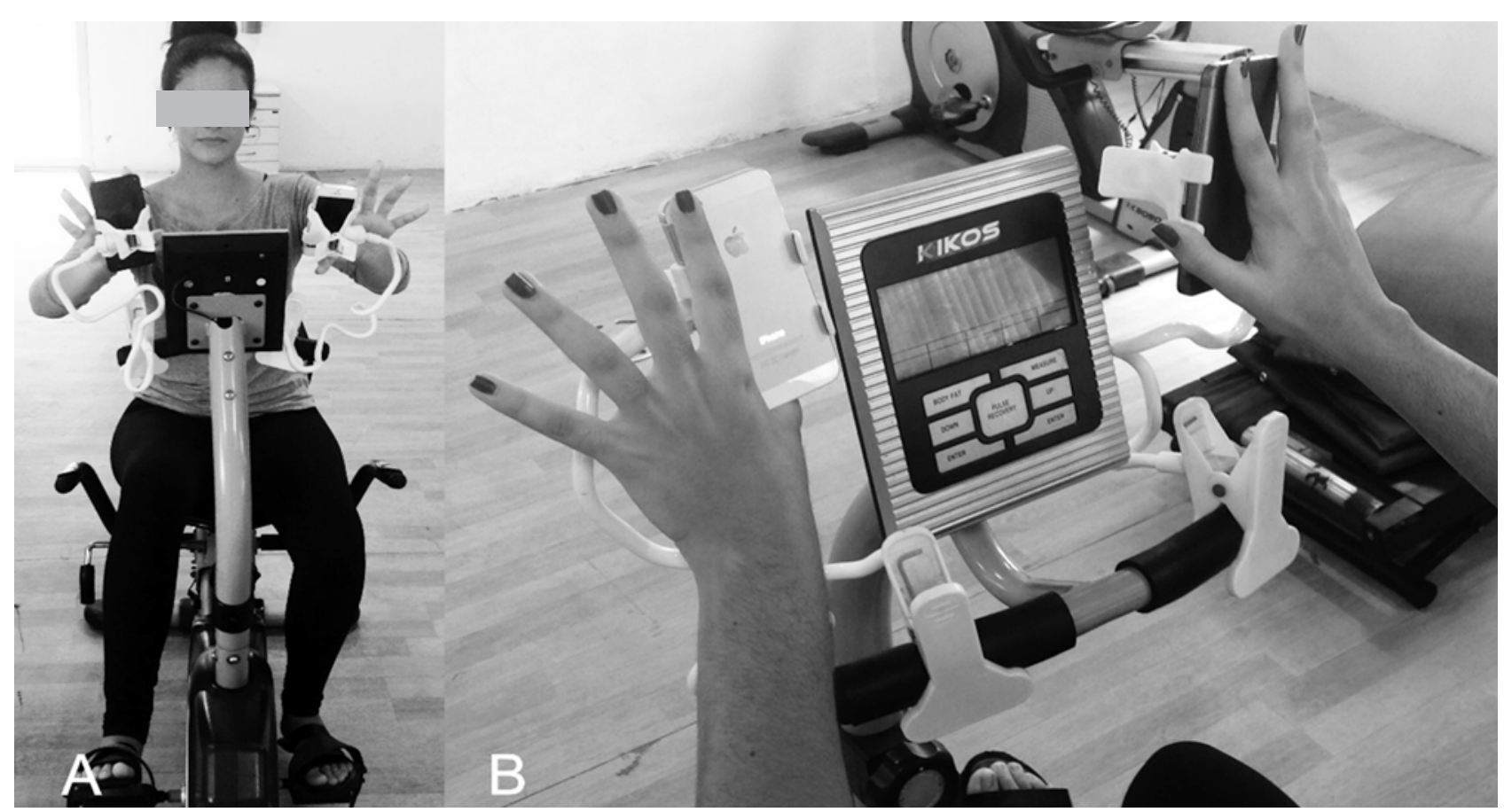

Figure 1. Support to the fixed smartphone (A). Position of fingers on smartphone sensors for heart rate measurement (B)

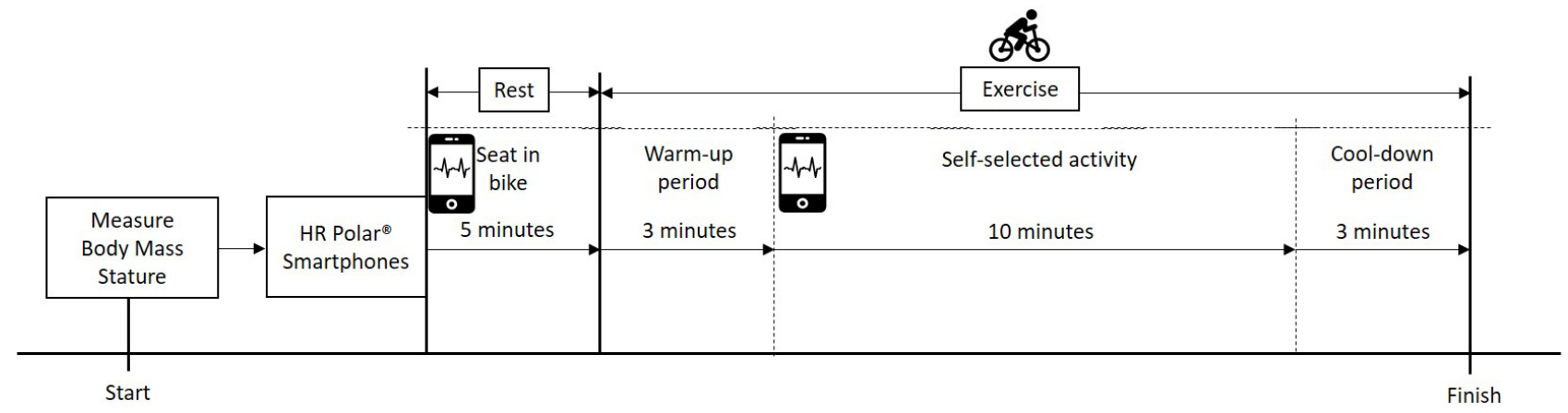

Figure 2. Study design

\section{Exercise session}

Continuous exercise was performed on a cycle ergometer (Kikos ${ }^{\circledR}$, HM 9090, Brazil) and was divided into 3 parts: a warm-up period ( $3 \mathrm{~min})$; a self-selected activity (10 $\mathrm{min})$; and a cool-down period (3 min). HR was measured each minute by using an HRM and the Instant Heart Rate ${ }^{\circledast}$ application on the iPhone/ $\mathrm{iOS}^{\circledast}$ and Lenovo/Android ${ }^{\circledast}$ smartphones simultaneously during the self-selected activity (Figure 2). We only considered the 10-min period of self-selected activity to analysis, obtaining 10 measurements for each instrument.

\section{Statistical analysis}

The descriptive analysis results are presented as means and standard deviations $(S D)$. The ShapiroWilk test was used to determine the normality of the data. To establish the criterion-concurrent validity, a Pearson correlation test of the HRM was performed in order to determine the reference measurement. The effect size (ES) was applied for a complementary analysis. A Bland-Altman plot served to verify the agreement of data. For all analyses, statistical significance of the results was accepted at $p<0.05$. The SPSS software (v. 20, IBM, USA) was used for the analyses, and GraphPad Prism 5 (GraphPad, USA) for the graphic design.

\section{Ethical approval}

The research related to human use has complied with all the relevant national regulations and institutional policies, has followed the tenets of the Declaration of Helsinki, and has been approved by the Research Ethics Committee of the Federal University of Pernambuco (No. 1.097.611). 
G. Vasconcelos et al., Smartphone application for measuring heart rate

\section{Informed consent}

Informed consent has been obtained from all individuals included in this study.

\section{Results}

Table 1 shows the correlation $(r)$ and $E S$ values for each smartphone operating system (Polar ${ }^{\circledast} \times$ Lenovo/ Android $^{\circledast}$, Polar $^{\circledast} \times$ iPhone iOS $\left.^{\circledast}\right)$. The validity was established by regression analysis between the criterion measure of $\mathrm{HR}_{\text {average }}$ and the HR measures of the smartphones, iPhone/iOS ${ }^{\circledast}$ and Lenovo/Android ${ }^{\circledR}$ (Figure 3). Correlations were considered strong with the values of $r=0.87(p=0.001)$ and $r=0.98(p=$ $0.001)$ for the iPhone $/$ iOS $^{\oplus}$ and Lenovo/Android ${ }^{\circledR}$ smartphones, respectively. The determination coefficient $\left(r^{2}\right)$ indicates that the linear regression between the HR obtained by the $\mathrm{HR}_{\text {average }}$ device and the iPhone $/ \mathrm{iOS}^{\circledR}$ smartphone explained $75 \%$ of the collected data, and the regression between the $\mathrm{HR}_{\text {average }}$ and the Lenovo/ Android ${ }^{\circledast}$ explained 95\%. Both smartphones presented good validity for HR measurements during the exercise; however, the Lenovo/Android ${ }^{\circledast}$ smartphone showed a better result (Figure 3).

The Bland-Altman plot (Figure 4) shows the data concordance for the 2 operating systems (iPhone $/ \mathrm{iOS}^{\circledR}$ and Lenovo/Android ${ }^{\circledR}$ ). In analysing the prediction errors of the smartphones (Bias), we verified that the average error was $5 \mathrm{bpm}(S D=8.0 \mathrm{bpm})$ for the iPhone $/ \mathrm{iOS}^{\oplus}$ and $-0.7 \mathrm{bpm}(S D=3.4 \mathrm{bpm})$ for the Lenovo/Android $^{\boxplus}$ from the analyses performed by using the Bland-Altman plot. These values indicated that the iPhone $/ \mathrm{iOS}^{\circledast}$ overestimated the measure, and the Lenovo/Android ${ }^{\circledR}$ underestimated the measure. Although the error was considered small for both instruments, the iPhone $/ \mathrm{iOS}^{\circledast}$ smartphone presented a broad range of values related to the differences between the Polar ${ }^{\circledR}$ HR value and the HR from the iPhone/ $\mathrm{iOS}^{\circledast}$, with a coefficient of variation of $62.5 \%$. The Lenovo/Android ${ }^{\circledast}$ smartphone presented a better mea-

Table 1. Reliability of HR measurement instruments

\begin{tabular}{lccc}
\hline $\begin{array}{l}\text { Reliability } \\
\text { analysis }\end{array}$ & ICC & ES & Classification \\
\hline $\begin{array}{l}\text { Lenovo/Android }^{\circledast} \\
\text { HR }\end{array}$ & $0.98(0.94 ; 0.99)$ & 0.00 & Trivial \\
\hline $\begin{array}{l}\text { iPhone/iOS } \\
\text { HR }\end{array}$ & $0.99(-0.95 ; 0.99)$ & 0.00 & Trivial \\
\hline
\end{tabular}

HR - heart rate, ICC - intra-class correlation coefficient, $E S$ - effect size

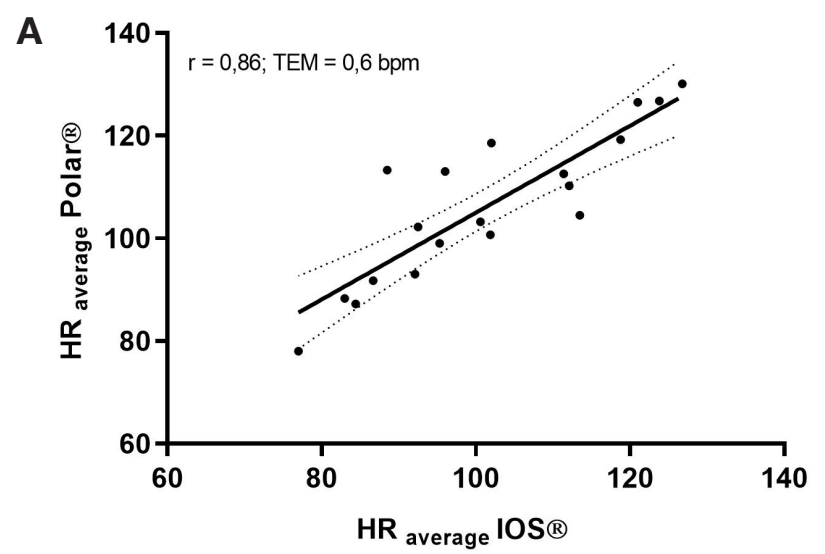

B

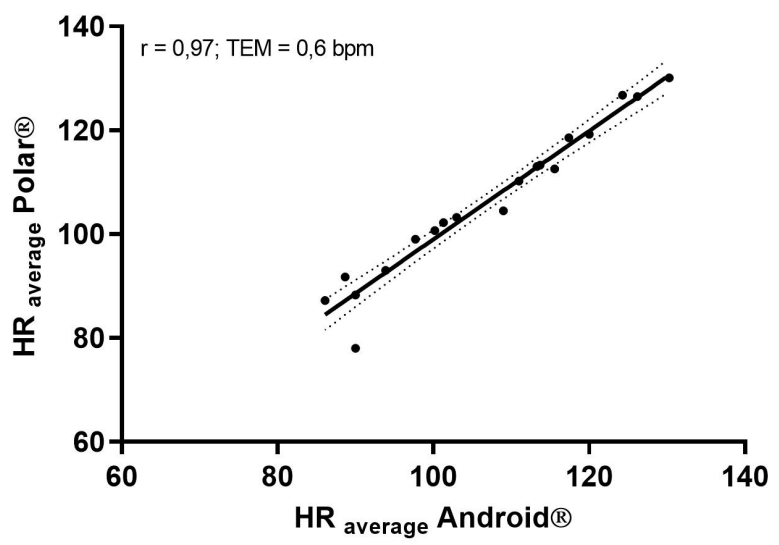

Figure 3. Linear regression between HR Polar ${ }^{\oplus}$ mean with HR iPhone $/ \mathrm{iOS}^{\oplus}$ mean (A) and with HR Lenovo/ Android $^{\boxplus}$ mean (B)

A

Diff (Polar $\otimes^{\circ}-$ IOS $\left.®\right)$
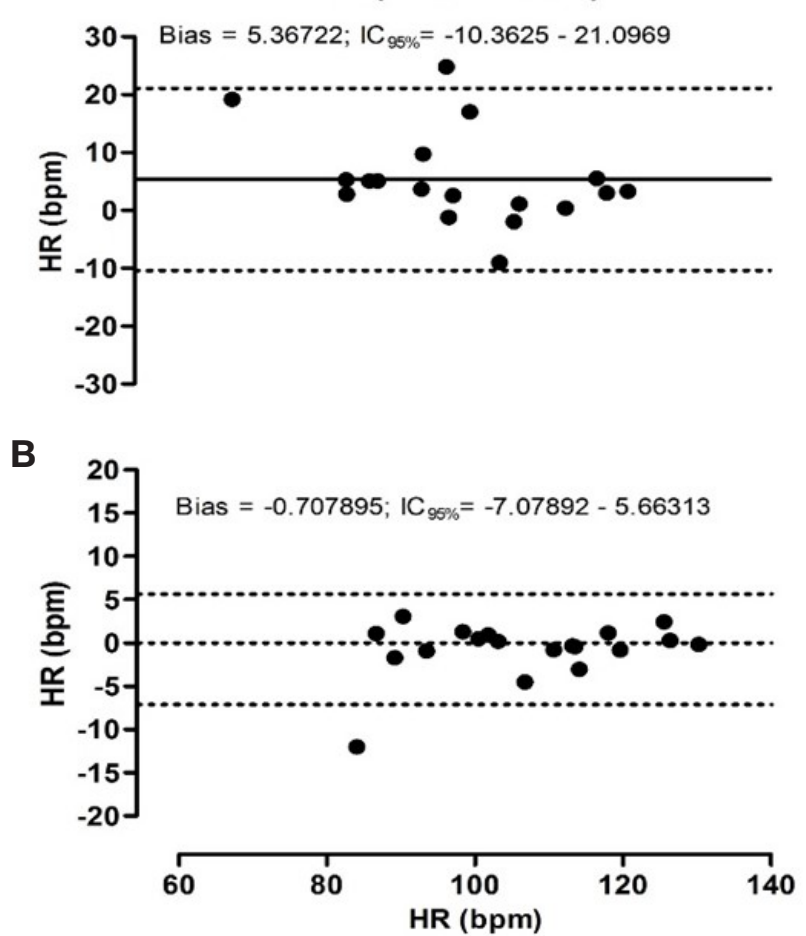

Figure 4. Bland-Altman plot of HR Polar ${ }^{\circledast}$ mean with HR iPhone/iOS ${ }^{\oplus}$ mean (A) and with HR Lenovo/ Android $^{\circledR}$ mean (B) 
surement with a $20 \%$ variation, which showed greater homogeneity and less dispersion than the iPhone/iOS ${ }^{\circledR}$. For both instruments, the mean error reported does not seem to compromise several measures that use $\mathrm{HR}$ as a parameter.

At the moment of analysis, both operating systems presented $E S$ values between trivial and moderate and we observed a high validity for most of the evaluated moments. However, when comparing the validity of iPhone $/$ iOS $^{\circledR}$ with that of Lenovo/Android ${ }^{\circledR}$, we noticed that there was greater agreement of the application for the device with the Lenovo/Android ${ }^{\circledR}$ system. The first moments for the 2 appliances were classified with a moderate $E S$, which could not identify the cause.

\section{Discussion}

We analysed HR validity obtained through smartphones with iPhone/iOS ${ }^{\circledR}$ and Lenovo/Android ${ }^{\circledR}$ operating systems with the help of the Instant Heart Rate ${ }^{\circledR}$ application. The present study is the first study to provide data regarding the validity of HR measurements obtained through smartphones without accessory dependence (thoracic band). Previous research [17, 18, $20,21]$ has already validated the measurement of HR variability by using smartphone applications, including the study by Esco et al. [14], in which the correlation between a smartphone finger pulse sensor and ECG was verified in 3 different positions (supine, sitting, and standing) during rest, with $r=0.98$. Another study correlated the same measurements in other conditions (sitting, reading, videogame) and found no differences between smartphone results when compared with ECG, presenting $r=0.99$ [22]. These studies evaluated only the correlation with the operating system of iPhone/iOS ${ }^{\circledR}$.

However, to perform these evaluations, accessories must be connected to the smartphone, which reduces the practical applicability of the measurement and increases the cost. In this study, there was no need for accessories to measure HR because of the structure of the smartphones, in which the video cameras are accompanied by tools that emit light beams. This construction allows to identify the reflection of the bio-optical image where the light source illuminates the target tissue and the emitted signal is detected by the smartphone camera $[15,16]$. This same mechanism is used by photoplethysmography, which is a noninvasive technique that detects changes in blood volume during a cardiac cycle and is normally used in peripheral regions of the body [16, 23, 24].

The HR measurement has a relevant impact during decision making for workload adjustment during exercise. That way, its precision should be considered as a sugnificant issue to be considered, especially for clinical populations. Utilizing the results of the present study to simulate the iPhone/iOS ${ }^{\circledast}$ estimation error in equations proposed by the American College of Sports Medicine [25], we verified that a variation of $13 \mathrm{bpm}$ in the measurement of maximum HR altered the speed by $0.8 \mathrm{~km} \cdot \mathrm{h}^{-1}$ on the treadmill, and a variation of $8 \mathrm{bpm}$ altered the speed by $0.5 \mathrm{~km} \cdot \mathrm{h}^{-1}$.

The application validated in this study presents itself as a new and easy tool for HR measurement. In addition, it is important to emphasize that mobile technology has become efficient in offering the possibility to monitor physiological variables both in ambulatory conditions and in exercise, thus contributing to the practical usefulness of this measurement since several applications available free recommend the use of HR for prescription and training monitoring and in most cases it is necessary to purchase Bluetooth tapes that have a higher cost. In addition, new applications that monitor HR during exercise or utilize it to perform maximal oxygen uptake predictive tests, for example, can use the platform as a base. With this, validating this application can promote a large scale HR employment, since the vast majority of the population already have smartphones and would not need to acquire new equipment.

Some limitations of the present study must be explained. The HR measurement may vary depending on the model of the smartphone and should be used with caution with other devices because there are variations in smartphone models regarding both the resolution of the camera and the intensity of the light beam (flash), which influences the accuracy of the HR measurement [15]. In addition, it is not possible to infer whether the differences in the results associated with the systems are caused by differences between the models or between the devices used. Finally, it is important to point out that the present study was conducted in a laboratory with a controlled temperature of $22^{\circ} \mathrm{C}$. Further studies are needed to investigate the accuracy of measurement at other temperatures.

\section{Conclusions}

We conclude that HR measurement, despite having become popular, continues to be limited to a significant population share. The results of the present study promote practical applications for coaches, clinicians, and physical exercise practitioners, who commonly use HR measurements for prescription and monitoring exercise in fitness and/or clinical contexts. Profession- 
G. Vasconcelos et al., Smartphone application for measuring heart rate

ally controlled HR can be run efficiently on smartphones through the Instant Heart Rate ${ }^{\circledast}$ application with the iPhone $/ \mathrm{iOS}^{\circledast}$ or Lenovo/Android ${ }^{\circledR}$ operating systems. In addition, the results will expand the use of this measure for people without access to HRMs, especially for populations that present some sensibility or cognitive impairment for information processing by mathematical strategies.

\section{Disclosure statement}

No author has any financial interest or received any financial benefit from this research.

\section{Conflict of interest}

The authors state no conflict of interest.

\section{References}

1. Ciolac EG, Guimarães GV, D’Avila VM, Bortolotto LA, Doria EL, Bocchi EA. Acute aerobic exercise reduces 24-h ambulatory blood pressure levels in long-termtreatedhypertensive patients. Clinics. 2008;63(6):753758; doi: 10.1590/s1807-59322008000600008.

2. Lamina S. Effects of continuous and interval training programs in the management of hypertension: a randomized controlled trial. J Clin Hypertens. 2010;12(11): 841-849; doi: 10.1111/j.1751-7176.2010.00315.x.

3. Swain DP, Parrott JA, Bennett AR, Branch JD, Dowling EA. Validation of a new method for estimating $\mathrm{VO}_{2 \max }$ based on $\mathrm{VO}_{2}$ reserve. Med Sci Sports Exerc. 2004;36(8):1421-1426; doi: 10.1249/01.mss.0000135 774.28494.19.

4. Borresen J, Lambert MI. The quantification of training load, the training response and the effect on performance. Sports Med. 2009;39(9):779-795; doi: 10.2165/ 11317780-000000000-00000.

5. Cole CR, Foody JM, Blackstone EH, Lauer MS. Heart rate recovery after submaximal exercise testing as a predictor of mortality in a cardiovascularly healthy cohort. Ann Intern Med. 2000;132(7):552-555; doi: 10.7326/0003-4819-132-7-200004040-00007.

6. Fox K, Borer JS, Camm AJ, Danchin N, Ferrari R, Lopez Sendon JL, et al. Resting heart rate in cardiovascular disease. J Am Coll Cardiol. 2007;50(9):823-830; doi: 10.1016/j.jacc.2007.04.079.

7. Achten J, Jeukendrup AE. Heart rate monitoring: applications and limitations. Sports Med. 2003;33(7): 517-538; doi: 10.2165/00007256-200333070-00004.

8. Bort-Roig J, Gilson ND, Puig-Ribera A, Contreras RS, Trost SG. Measuring and influencing physical activity with smartphone technology: a systematic review. Sports Med. 2014;44(5):671-686; doi: 10.1007/ s40279-014-0142-5.

9. Cerrito A, Bichsel L, Radlinger L, Schmid S. Reliability and validity of a smartphone-based application for the quantification of the sit-to-stand movement in healthy seniors. Gait Posture. 2015;41(2):409-413; doi: 10.1016/j.gaitpost.2014.11.001.

10. Stanton R, Wintour SA, Kean CO. Validity and intrarater reliability of MyJump app on iPhone 6s in jump performance. J Sci Med Sport. 2017;20(5):518-523; doi: 10.1016/j.jsams.2016.09.016.

11. Derhon V, Santos RA, Brandalize M, Brandalize D, Rossi LP. Intra- and inter-examiner reliability in angular measurements of the knee with a smartphone application. Hum Mov. 2017;18(2):38-43; doi: 10.1515/ humo-2017-0011.

12. Losa-Iglesias ME, Becerro-de-Bengoa-Vallejo R, Becerro-de-Bengoa-Losa KR. Reliability and concurrent validity of a peripheral pulse oximeter and health-app system for the quantification of heart rate in healthy adults. Health Informatics J. 2016;22(2):151-159; doi: $10.1177 / 1460458214540909$.

13. Vashist SK, Schneider EM, Luong JH. Commercial smartphone-based devices and smart applications for personalized healthcare monitoring and management. Diagnostics. 2014;4(3):104-128; doi: 10.3390/ diagnostics4030104.

14. Esco MR, Flatt AA, Nakamura FY. Agreement between a smartphone pulse sensor application and electrocardiography for determining lnRMSSD. J Strength Cond Res. 2017;31(2):380-385; doi: 10.1519/JSC. 0000000000001519.

15. Jonathan E, Leahy M. Investigating a smartphone imaging unit for photoplethysmography. Physiol Meas. 2010;31(11):N79-N83; doi: 10.1088/0967-3334/31/ 11/N01.

16. Matsumura K, Yamakoshi T. iPhysioMeter: a new approach for measuring heart rate and normalized pulse volume using only a smartphone. Behav Res Methods. 2013;45(4):1272-1278; doi: 10.3758/s13428-0120312-z.

17. Coppetti T, Brauchlin A, Müggler S, Attinger-Toller A, Templin C, Schönrath F, et al. Accuracy of smartphone apps for heart rate measurement. Eur J Prev Cardiol. 2017;24(12):1287-1293; doi: 10.1177/2047487317702 044.

18. Bouts AM, Brackman L, Martin E, Subasic AM, Potkanowicz ES. The accuracy and validity of iOS-based heart rate apps during moderate to high intensity exercise. Int J Exerc Sci. 2018;11(7):533-540.

19. Mitchell K, Graff M, Hedt C, Simmons J. Reliability and validity of a smartphone pulse rate application for the assessment of resting and elevated pulse rate. Physiother Theory Pract. 2016;32(6):494-499; doi: 10.1080/09593985.2016.1203046.

20. Nunan D, Donovan G, Jakovljevic DG, Hodges LD, Sandercock GR, Brodie DA. Validity and reliability of short-term heart-rate variability from the Polar S810. Med Sci Sports Exerc. 2009;41(1):243-250; doi: 10.1249/MSS.0b013e318184a4b1.

21. Flatt AA, Esco MR. Validity of the ithlete ${ }^{\mathrm{TM}}$ smart phone application for determining ultra-short-term heart rate 
variability. J Hum Kinet. 2013;39:85-92; doi: 10.2478/ hukin-2013-0071.

22. Gregoski MJ, Mueller M, Vertegel A, Shaporev A, Jackson BB, Frenzel RM, et al. Development and validation of a smartphone heart rate acquisition application for health promotion and wellness telehealth applications. Int J Telemed Appl. 2012;2012:696324; doi: $10.1155 / 2012 / 696324$.

23. Jonathan E, Leahy MJ. Cellular phone-based photoplethysmographic imaging. J Biophotonics. 2011;4(5): 293-296; doi: 10.1002/jbio.201000050.

24. Shelley KH. Photoplethysmography: beyond the calculation of arterial oxygen saturation and heart rate. Anesth Analg. 2007;105(6 Suppl.):S31-S36; doi: 10.1213/01. ane.0000269512.82836.c9.

25. ACSM. ACSM's guidelines for exercise testing and prescription. Baltimore: Lippincott Williams \& Wilkins; 2014. 